\title{
Elementos subjacentes aos regulamentos e a divulgação do risco de crédito em fundos de investimento em direitos creditórios
}

\author{
Elements underlying regulations and disclosure of credit risk in credit rights \\ investment funds
}

Elementos subyacentes a los reglamentos y la divulgación del riesgo de crédito en fondos de inversión en derechos de crédito

\section{Evelini Lauri Morri Garcia}

Mestre em Ciências Contábeis pela Universidade Estadual de Maringá (UEM)

Professora do Departamento de Ciências Contábeis da Universidade Estadual de Maringá -

Campus Regional de Cianorte - CRC (UEM)

Endereço: Rua D. Pedro II, 598, Zona 01

CEP: 87200-055 - Cianorte/PR - Brasil

E-mail: evelinilaurimorri@ hotmail.com

Telefone: (44)3619-4000

\section{Romildo de Oliveira Moraes}

Doutor em Controladoria e Contabilidade pela Universidade de São Paulo (USP)

Professor do Programa de Pós-Graduação em Ciências Contábeis da Universidade Estadual de Maringá - PCO (UEM)

Endereço: Avenida Colombo, 5790, Zona 07

CEP: 87020-900 - Maringá/PR - Brasil

E-mail: romoraes@uem.br

Telefone: (44)3011-4904

Artigo recebido em 03/11/2017. Revisado por pares em 06/04/2019. Reformulado em 24/03/2020. Recomendado para publicação em 24/03/2020 por Carlos Eduardo Facin Lavarda (Editor-Chefe). Publicado em 30/03/2020. 


\title{
Resumo
}

O objetivo do estudo é analisar a influência de elementos subjacentes à regulação contábil na evidenciação do risco de crédito praticada pelos Fundos de Investimentos em Direitos Creditórios (FIDCs). A amostra é composta por 148 FIDCs cujas notas explicativas de 2012 a 2014 foram analisadas quanto ao nível de atendimento das normas de evidenciação por meio de análise de conteúdo e testes estatísticos. Os resultados indicam que os FIDCs atendem parcialmente aos requisitos normativos de evidenciação do risco de crédito, que houve relativa melhoria no nível de divulgação ao longo do tempo, que o atendimento da ICVM n ${ }^{\circ}$ 489/11 é maior em relação ao CPC 40 (R1) e que critérios normativos quantitativos são os aspectos mais divulgados. Os constructos da Teoria da Informação Assimétrica permitem compreender que a assimetria de informações do risco de crédito permanece no mercado de securitização e que a especificidade dos regulamentos influencia a sua ocorrência.

Palavras-chave: Securitização; Evidenciação; Risco de crédito

\begin{abstract}
The objective of this study is to analyze the influence of elements underlying accounting regulation in the disclosure of credit risk practiced by Credit Rights Investment Funds (FIDCs). The sample consists of 148 FIDCs whose explanatory notes from 2012 to 2014 were analyzed as to the level of compliance with disclosure standards through content analysis and statistical tests. The results indicate that the FIDCs partially meet the regulatory requirements for disclosure about credit risk, that there has been a relative improvement in the level of disclosure over time, that compliance with ICVM n $n^{\circ} 899 / 11$ is higher than CPC 40 (R1), and that quantitative normative criteria are the most publicized aspects. The constructs of the Asymmetric Information Theory allow us to understand that the asymmetry of credit risk information remains in securitization market and that the specificity of the regulations influences its occurrence.
\end{abstract}

Keywords: Securitization; Disclosure; Credit risk

\section{Resumen}

El objetivo del estudio es analizar la influencia de elementos subyacentes a la regulación contable en la evidencia del riesgo de crédito practicada por los Fondos de Inversiones en Derechos de Crédito (FIDCs). La muestra está compuesta por 148 FIDCs cuyas notas explicativas de 2012 a 2014 fueron analizadas cuanto al nivel de atención de las normas de evidencia por medio de análisis de contenido y pruebas estadísticas. Los resultados indican que los FIDCs atienden parcialmente a los requisitos normativos de evidencia sobre el riesgo de crédito, que hubo relativa mejora en el nivel de divulgación a lo largo del tiempo, que la atención de la ICVM no 489/11 es mayor en relación al CPC $40(R 1)$ y que los criterios normativos cuantitativos son los aspectos más publicitados. Los constructos de la Teoría de la Información Asimétrica permiten comprender que la asimetría de informaciones del riesgo de crédito permanece en el mercado de securitización y que la especificidad de los reglamentos influye en su ocurrencia.

Palabras clave: Securitización; Evidencia; Riesgo de crédito

\section{Introdução}

A securitização é uma estruturação financeira que emite títulos lastreados em recebíveis transferidos de originadores à entidade securitizadora (GORTON, SOULELES, 2007; PINHEIRO, 2008). Em vista da possível inadimplência destes recebíveis, o risco de crédito é uma informação que deve ser evidenciada pelas securitizadoras, considerando que é o principal tipo de risco que os investidores da securitização estão expostos (COELHO, BORELLI, 2012; CVM, 2014; MICHALAK, UHDE, 2012; PINHEIRO, 2008). 
A literatura prévia apontou que as finanças estruturadas não têm evidenciado informações precisas ao mercado sobre os riscos das suas operações (CERBIONI, FABRIZI, PABONETTI, 2015; CHEN, LIU, RYAN, 2008; MICHALAK, UHDE, 2012). Inclusive, o déficit de informações sobre riscos também é identificado em empresas de outros setores e é percebido em países de todo o mundo (ABRAHAM, COX, 2007; DOBLER, 2008; LAJILI, ZEGHAL, 2005; LINSLEY, SHRIVES, 2006; OTHMAN, AMEER, 2009; SHINZATO, 2011).

Devido ao reconhecido contexto de baixo nível de divulgação voluntária de informações, regulamentos de evidenciação assumem importância ao determinar compulsoriamente parâmetros que os relatórios financeiros dos fundos de investimento em direitos creditórios (FIDCs), estrutura de securitização mais desenvolvida no Brasil, devem atender para que sejam minimamente transparentes (CAMARA, GALDI, 2013; FAVERO JUNIOR, 2014; FERABOLLI, 2014; FERNANDES, SHENG, LORA, 2014; PINHEIRO, 2008). Os padrões de divulgação de informações sobre instrumentos financeiros modelados pelas finanças estruturadas são representados no Brasil pelo Pronunciamento CPC 40 (R1), aplicável a todas as entidades, e pela Instrução $n^{\circ}$ 489/11 da Comissão de Valores Mobiliários (CVM), direcionada exclusivamente aos FIDCs. Estes regulamentos, apesar de emitidos por órgãos distintos, impõem a evidenciação do risco de crédito com o intuito de subsidiar a redução da assimetria de informações e contribuir com a consolidação da securitização brasileira (CVM, 2014).

A economia da informação é um campo de estudos que investiga os efeitos da ausência de informações, visto que esta gera seleção adversa e afasta investidores, causando deterioração da economia (STIGLITZ, 2002; SPENCE, 2002). Os constructos da Teoria da Informação Assimétrica sustentam que a divulgação de informações completas é um importante precursor de equilíbrio no mercado. Por consequência, a sonegação de informações desencadeia distúrbios nas relações entre agentes, pressupondo que estes possuem níveis diferenciados de conhecimento prévio sobre as operações, contexto propício a altos níveis de incerteza e oportunismo (AKERLOF, 1970; STIGLITZ, 2000). Isto se tornou evidente empiricamente quando a atividade de securitização foi apontada como responsável pela crise dos subprimes em 2007 devido ausência de informações sobre os riscos assumidos pelos investidores, o que impossibilitou a detecção de securitizações de títulos ilíquidos e gerou perdas generalizadas (BROWN, 2010; SCHWARCZ, 2009).

Com o intuito de minimizar a assimetria de informação entre agentes, as normas de contabilidade são dispositivos de enforcement na publicidade das informações dos FIDCs apoiando a sustentabilidade destas transações no mercado financeiro (CVM, 2014). Porém, o baixo nível de qualidade das informações sobre risco de crédito percebido em diversos setores, e, inclusive no setor de securitização, suscita questionamento sobre a eficácia dos regulamentos enquanto instrumento de diluição da assimetria informacional. Stiglitz (2000) defende que novas dimensões e abordagens sobre a disponibilização de informações devem ser verificadas, e, por isso, emerge a indagação de quais elementos potencializam a adesão ou desacato de distintas normas de evidenciação. Baseada neste contexto, a questão de pesquisa fundamenta-se em: Qual a influência de elementos subjacentes à regulação contábil na evidenciação do risco de crédito praticada pelos FIDCs?

O objetivo do estudo é analisar a influência de elementos subjacentes à regulação contábil na evidenciação do risco de crédito praticada pelos FIDCs. Para isso, o nível de atendimento dos requisitos de normas contábeis sobre a divulgação do risco de crédito foi levantado considerando características das normas contábeis que regem os procedimentos de disclosure. Os dados obtidos foram analisados sob a perspectiva dos pressupostos da Teoria da Informação Assimétrica.

A pesquisa proposta atua na investigação da lacuna existente acerca da assimetria de informação do risco de crédito na securitização e sua relação com a função informativa da contabilidade sustentada pelas normas de evidenciação. Como os regulamentos de evidenciação têm o papel de reduzir a assimetria de informação, a presente pesquisa avalia o disclosure praticado 
considerando a implementação obrigatória destes instrumentos pelos FIDCs e busca compreender como a estrutura das normas influencia a sua adesão. A ausência de discussões teórico-empíricas específicas sobre a influência das características das normas de contabilidade é uma oportunidade de estudo sobre o papel da formatação da regulamentação no engajamento das organizações às premissas contábeis. A presença de risco de crédito na securitização apresenta-se como um ambiente propício a esta investigação devido os debates públicos sobre segurança em títulos de securitização e devido a subordinação dos FIDCs às exigências contábeis de dois órgãos reguladores distintos.

Os resultados encontrados demonstraram que parte dos requisitos sobre risco de crédito de ambos os regulamentos, CPC 40 (R1) e ICMV nº 489/11, não são atendidos, indicando ausência de informações cuja divulgação é compulsória e esperada pelo mercado. Destaca-se que a observação do CPC 40 (R1) é menor em relação a ICVM no 489/11. Os resultados também demonstraram que, em geral, o atendimento das normas foi ampliado ao longo do tempo. Identificou-se que há diferenças significativas na divulgação de informações qualitativas e quantitativas indicando que formatos específicos de informações estão atrelados à ausência de informações públicas. O estudo apresenta contribuições empíricas ao suscitar discussões sobre a eficácia da normatização relativa ao risco de crédito da securitização. A análise ainda promove o debate sobre a influência que distintos órgãos emissores de normas detêm e como a atuação destes pode expandir a utilidade dos regulamentos de evidenciação.

Os constructos dados pela Teoria da Informação Assimétrica foram testados empiricamente, e, convergindo com Stiglitz (2000), os resultados permitem defender que o estudo de dimensões e abordagens da oferta de informação baseadas em exigências normativas pode oferecer compreensão dos gargalos ainda presentes na securitização que geram falhas de mercado neste segmento. Os resultados apresentados permitem contribuições teóricas ao oferecer um diálogo sobre o papel intervencionista dos regulamentos de cunho contábil e a sua eficácia substanciada por elementos que não tem recebido atenção pela literatura acadêmica.

\section{Teoria da Informação Assimétrica e a Divulgação de Informações sobre o Risco de Crédito}

A assimetria da informação é a diferença na posse de informações entre agente e principal que ocasiona falhas de mercado, como a seleção adversa e o risco moral (BROWN, 2010). Akerlof (1970) relaciona as falhas de mercado com a ausência de comunicação pelos vendedores do real valor dos produtos que estão vendendo. Admite-se que a ausência de informações de qualidade pode prejudicar as estruturações realizadas pelo mercado financeiro, visto que os investidores buscam por investimentos rentáveis e mais seguros (HEALY; PALEPU, 2001). Para atender esta demanda, a economia da informação defende que as informações devem estar disponíveis ao mercado, visto que podem determinar a relação entre os produtos e seus possíveis compradores (MILGROM, 1981).

Stiglitz (2000) argumenta que é preciso considerar a imperfeição das informações porque sempre permanece algum grau de assimetria cuja extensão é afetada por ações de empresas e indivíduos. Para isso, destaca conjunturas que devem ser avaliadas: (i) o ponto de partida sobre o estudo da economia da informação deve ser a investigação sobre como a economia adapta-se a novas informações e cria novos conhecimentos e como esse conhecimento é disseminado, absorvido e utilizado em toda a economia; (ii) há muitas dimensões e abordagens sobre a informação que devem ser verificadas; (iii) a informação relevante deve contemplar diferentes abordagens e deve ser qualitativa e quantitativa, quando necessário; (iv) a informação transmitida por meio de preços não é apenas relacionada com a escassez; (v) todas as ações empregadas pelas empresas refletem na geração de informações ao mercado, mesmo que indiretamente, e o seu comportamento afeta estas informações em uma infinidade de maneiras; (vi) a economia de mercado não é totalmente equilibrada; (vii) a economia da informação apresenta explicações para 
os fenômenos e instituições para as quais a teoria padrão não fornece nenhuma explicação conciliando, inclusive, a informação imperfeita; e, (viii) as forças de mercado também podem criar informações irreais que induzem a dispersões de preços ou instigam as organizações a reter informações.

É esperado que a escolha de investimentos seja calcada na avaliação dos seus riscos, porém, tal informação nem sempre está disponível ou é clara, quando disponibilizada. Brown (2010) relata que a assimetria de informação sobre os riscos está presente no mercado de securitização. Operações complexas que envolvem diversas particularidades dificultam a compreensão dos critérios que regem a transferência de ativos, gerando opacidade informacional, que por sua vez, influencia a assimetria de informação por meio de risco sistêmico e risco moral (CHENG; DHALIWAL; NEAMTIU, 2008).

Schwarcz (2009) explica que o risco moral da securitização existe na motivação que o originador tem de transferir ativos "podres" quando os demais participantes da securitização não conseguem vislumbrar o nível de perdas esperadas com a mesma acuracidade do originador. A securitização também pode levar à seleção adversa, pois, o originador do crédito possui conhecimento sobre os riscos de crédito dos ativos securitizados e a evidenciação pode não possuir a capacidade de transmitir informações aos investidores com a mesma qualidade que os originadores possuem (AGARWAL; CHANG; YAVAS, 2012). Isto, segundo Healy e Palepu (2001), eleva o custo de capital e afasta os investidores.

A assimetria de informação na atividade de securitização justifica a busca por ferramentas de proteção alternativas, como por exemplo, a coobrigação do emissor dos recebíveis (SCHWARCZ, 2009). Isso acontece porque são necessários sinais para transportar informações persistentemente em equilíbrio de vendedores para compradores, ou entre aqueles com mais para aqueles com menos informação (SPENCE, 2002). Contudo, Stiglitz (2000) relata que a sinalização efetuada pelas empresas, apesar de ser relevante, não é suficiente, o que faz o mercado estar sempre em evolução, buscando formas de incentivar a divulgação das informações que necessita.

A economia da informação está diretamente ligada aos demonstrativos financeiros (VERRECCHIA, 2001). As reformas na normatização contábil visa, entre outros motivos, reduzir a assimetria informacional, visto que novos mecanismos de proteção podem ser dispendiosos para as entidades (BROWN, 2010). Sem a interferência de órgãos de controle, a imperfeição de mercado seria majorada e causaria ainda mais riscos. Por isso, espera-se que reguladores intervenham a fim de oportunizar mais equilíbrio a este ambiente por meio do disclosure contábil compulsório (DANTAS et al., 2005).

\subsection{Hipóteses}

Entre as pesquisas que investigaram o nível de evidenciação de informações dos riscos observa-se que prevalece a conclusão de que há baixo nível de atendimento das normas de divulgação. Lajili e Zeghal (2005) analisaram as demonstrações financeiras de empresas canadenses e observaram que informações quantitativas sobre os riscos eram escassas e assimétricas. Linsley e Shrives (2006) investigaram empresas do Reino Unido e obtiveram os mesmos resultados apresentados por Lajili e Zeghal (2005).

Amran, Bin e Hassan (2009) identificaram níveis de evidenciação de riscos de empresas da Malásia inferiores aos resultados encontrados por Lajili e Zeghal (2005). Othman e Ameer (2009) encontraram que o risco de crédito é a categoria menos mencionada entre os riscos de mercado de instrumentos financeiros nas demonstrações financeiras de empresas da Malásia. Rajab e Handley-Schachler (2009) avaliaram os níveis de evidenciação de informações sobre o risco no Reino Unido. Encontraram que, apesar de haver uma melhoria da divulgação ao longo do tempo, o disclosure não atende aos critérios normativos. 
Em Portugal, Pinto e Lemos (2013) encontraram baixo nível de evidenciação de informações de risco em instituições financeiras. No Brasil, Dantas et al. (2010) avaliaram o disclosure do risco de crédito pelos bancos e identificaram que o nível de atendimento das normas de divulgação é baixo, ficando em torno de 40\%. Maia, Formigoni e Silva (2012) identificaram que o atendimento dos critérios normativos de evidenciação compulsória por empresas brasileiras é de 67,5\%. Oliveira, Rodrigues e Craig (2011) identificaram que a adoção de normas internacionais de contabilidade não colaborou com os níveis de evidenciação de riscos no Brasil. Esta mesma conclusão foi obtida por Shinzato (2011) que demonstrou que não houve melhoria quanto à transparência na divulgação da exposição do risco crédito com adoção das normas internacionais de contabilidade por empresas brasileiras.

Dobler (2008) relata que o baixo nível de evidenciação do risco é um evento esperado visto que as informações de risco podem expor as estratégias gerenciais, deixando a entidade vulnerável em relação à concorrência de mercado. Por este motivo, se deixa de divulgar informações desta natureza, ainda que sejam requeridas pelos investidores e demais stakeholders. Na Espanha, Domínguez e Gámez (2014) encontram resultados semelhantes.

Quanto às atividades de securitização, Cheng, Dhaliwal e Neamtiu (2008) concluíram em sua pesquisa que existe opacidade de informações. Nesta pesquisa as operações de securitização foram avaliadas sob a perspectiva da assimetria informacional ao buscar compreender a discordância entre diferentes investidores acerca da essência da informação emitida sobre os riscos das operações realizadas por securitizadoras. Barth e Landsman (2010) encontraram que as entidades securitizadoras não divulgam informações suficientes para que os investidores possam avaliar adequadamente o nível de risco transferido aos seus investimentos. Estas conclusões levam ao pressuposto de que as demonstrações financeiras dos FIDCs não efetuam todas as divulgações de informações, sobre risco de crédito, exigidas pelas normas contábeis. Considerando os resultados de pesquisas precedentes, estrutura-se a seguinte hipótese: $\mathbf{H}_{\mathbf{1}}$ - A evidenciação de informações sobre o risco de crédito dos títulos de FIDCs é inferior aos requisitos normativos.

A instituição de regulamentos contábeis tem o intuito de aumentar a quantidade e a qualidade das informações divulgadas pelas entidades e este incremento é esperado que ocorra progressivamente ao longo do tempo (LEUZ; VERRECCHIA, 2000). A teoria da informação assimétrica defende a necessidade de investigação da adaptação das entidades para divulgar novas informações a fim de que se compreenda os efeitos destas nas decisões praticadas pelo mercado e as repercussões na economia (STIGLITZ, 2000). Estudos anteriores efetuaram a análise da influência do tempo de emissão das normas que regulamentam a divulgação de informações sobre riscos. Rajab e Handley-Schachler (2009) constataram uma tendência crescente na divulgação de informações sobre riscos ao longo do tempo, cuja principal influência foi a instituição da regulação contábil com padronização internacional e as recomendações dos institutos de contabilidade. Contudo, Amran et al. (2009) mostraram que a implantação de regulamentos não elevou a qualidade da evidenciação. No Brasil, Dantas et al. (2010) identificaram que o atendimento de critérios normativos de evidenciação de risco de crédito de bancos cresceu constantemente a partir da vigência dos regulamentos. Estes resultados sustentam a seguinte hipótese: $\mathbf{H}_{2}-\mathbf{O}$ nível de atendimento dos critérios de divulgação do risco de crédito aumentou ao longo do tempo de vigência das normas de divulgação.

Abraham e Cox (2007) indicaram que o nível de evidenciação de risco é influenciado pela regulação existente. Contudo, Cerbioni, Fabrizi e Parbonetti (2015) demonstraram que securitizadoras italianas não atenderam adequadamente aos critérios de divulgação dos instrumentos financeiros e sugerem que normas específicas sobre securitização podem colaborar com uma melhor evidenciação sobre as condições destes ativos.

O reconhecimento da assimetria de informação no mercado de securitização suscitou interesse da CVM em emitir regulamentos específicos para esta atividade (CVM, 2014). No Brasil, 
as regras gerais de divulgação acerca dos instrumentos financeiros já estavam presentes no CPC 40. Entretanto, a emissão da ICVM no 489/11 ocorreu com o intuito de definir parâmetros de registro contábil e evidenciação exclusivos às atividades de securitização, a fim de que haja um padrão informativo neste segmento. Garcia, Fadel e Moraes (2015) identificaram que o nível de cumprimento dos critérios normativos de evidenciação do risco de crédito constantes na ICVM n ${ }^{\circ}$ 489/11 é superior em relação aos requisitos presentes no CPC 40 devido sua especificidade. Estas evidências sugerem que o nível de atendimento dos critérios de divulgação do risco de crédito definidos pela ICVM n ${ }^{\circ}$ 489/11 é maior em relação ao atendimento dos critérios do CPC 40 e levam a formular a seguinte hipótese: $\mathrm{H}_{3}$ - $\mathrm{O}$ nível de atendimento dos critérios de divulgação do risco de crédito definidos pela ICVM nº 489/11 é maior em relação ao atendimento dos critérios do CPC 40.

Ao analisar os estudos sobre evidenciação de riscos, pode-se identificar que há predominância de resultados que indicam baixo nível de divulgação quantitativa de riscos, ainda que sejam requisitos compulsórios de divulgação. Lajili e Zéghal (2005), Linsley e Shrives (2006) e Othman e Ameer (2009) convergem quanto a este entendimento, a partir dos resultados apresentados por suas pesquisas. No Brasil, Silva, Machado e Hein (2013) avaliaram critérios de divulgação determinados pelo CPC 40 e encontraram que a divulgação atende critérios qualitativos, mas, normalmente, não atendem aos critérios quantitativos.

Dobler (2008) relata que as empresas apresentam dificuldade para mensurar seus riscos, e, por isso, evitam oferecer informações que podem ser incorretas. Isto indica que o nível de evidenciação do risco de crédito tende a ser formado, principalmente, pelo atendimento de critérios qualitativos e que este aspecto pode apresentar maior divulgação em relação aos aspectos quantitativos. Estes argumentos permitem estruturar a seguinte hipótese: $\mathbf{H}_{4}$ - O nível de divulgação do risco de crédito é maior em critérios normativos qualitativos em relação aos aspectos quantitativos de evidenciação.

\section{Procedimentos Metodológicos}

A população da pesquisa é composta por todos os FIDCs de créditos padronizados atuantes no Brasil, do ano de 2012 ao ano de 2014. A identificação foi realizada por meio de área específica do site da CVM que disponibiliza demonstrativos com informações sobre a atuação dos FIDCs, entre eles, as demonstrações financeiras. Para a atual pesquisa, foram utilizadas notas explicativas como fonte de dados.

A partir da consulta realizada no site da CVM, no dia 27 de Junho de 2015, foram encontrados 293 FIDCs registrados, ou seja, que estavam em situação ativa nesta data. No entanto, foi preciso verificar a existência de fundos que encerraram suas atividades no ano de 2015, porém, que estavam ativos em períodos anteriores. A fim de atender esta necessidade, no site da CVM existe campo específico de busca de fundos que foram encerrados, o qual foi usado para identificar os FIDCs nesta situação. Por meio da análise dos FIDCs cancelados, foram identificados 79 fundos que estavam ativos no período de 2012 a 2014. Isto faz reconhecer que a população de FIDCs para o período de análise desta pesquisa é formada por 372 fundos, configurando, assim, um universo finito.

A amostragem foi determinada por método não probabilístico intencional. Devido o uso de testes comparativos entre distintas subamostras, foi necessário excluir os FIDCs que não apresentaram demonstrações financeiras, obrigatoriamente, em todos os três exercícios que compõem o aspecto temporal da pesquisa. Estas exclusões referem-se a fundos que iniciaram suas atividades após o exercício de 2012, ou, encerraram as atividades antes do término do exercício de 2014. Foram retirados da amostra 130 fundos que se encontravam em uma destas situações. Além disso, foi identificado que alguns fundos, ainda que declarados como ativos durante o período analisado, não publicaram suas demonstrações financeiras. Estes totalizaram 48 FIDCs e 
foram retirados da amostra. Também foi percebida a presença de FIDCs que atuavam com créditos não padronizados (vencidos), e, devido as distintas características de riscos destes recebíveis, optou-se por excluí-los da amostra, representando 42 FIDCs. Por fim, foram retirados os FIDCs que contemplavam ativos a performar, e, devido a ausência de informações sobre esta modalidade de securitização, optou-se por excluí-los da amostra. Foram identificados 4 FIDCs com esta característica, fazendo com que a amostra final fosse formada por 148 FIDCs.

A pesquisa, quanto aos seus objetivos, é classificada como descritiva. Este tipo de pesquisa permite analisar e correlacionar registros sem manipulá-los, averiguando como que ocorre tal fenômeno, além de explicar e descrever as características de determinada população ou fenômeno, ou então, o estabelecimento de relações entre variáveis (GIL, 2010). A fim de que o objetivo seja atendido, utiliza-se abordagem quantitativa para que se possa prever estatisticamente a proximidade dos conceitos (DENCKER; VIÁ, 2001). Os procedimentos de coleta de dados se configuraram como pesquisa documental e levantamento, sendo as ações empregadas para reunir informações (MARTINS; THEÓPHILO, 2009).

Para realizar a organização e análise dos dados empregou-se análise de conteúdo que é um conjunto de técnicas de análise das comunicações que utiliza critérios sistemáticos e objetivos de descrição do conteúdo das mensagens. Esta técnica emprega hermenêutica baseada na dedução, oscilando entre o rigor da objetividade e a fecundidade da subjetividade (BARDIN, 2006). Para obter e categorizar os dados foram utilizados critérios de divulgação do risco de crédito exigidos pelos instrumentos normativos (CPC 40 (R1) e ICVM n n $^{\circ} 89 / 11$ ) que indicam quais informações devem ser divulgadas por FIDCs e qual o nível de detalhamento deve ser atendido, conforme demonstrado no Quadro 1 e no Apêndice.

\begin{tabular}{|c|c|c|c|c|c|}
\hline \multicolumn{3}{|c|}{ CPC 40 (R1) } & \multicolumn{3}{|c|}{ ICVM n $^{\circ} 489 / 11$} \\
\hline \multicolumn{2}{|c|}{ Descrição } & \multirow{2}{*}{$\begin{array}{c}\text { Aspecto } \\
\text { Quantitativo }\end{array}$} & \multicolumn{2}{|r|}{ Descrição } & \multirow{2}{*}{$\begin{array}{c}\text { Aspecto } \\
\text { Qualitativo }\end{array}$} \\
\hline 1 & Item 8 & & 1 & Inciso I, $\S 8^{\circ}$, Art. 17 & \\
\hline 2 & Item 15 & Quantitativo/Qualitativo & 2 & Inciso III (a) e IV (a), $\S 8^{\circ}$, Art. 17 & Qualitativo \\
\hline 3 & Item 16 & Quantitativo & 3 & Inciso III (b) e IV (b), $\S 8^{\circ}$, Art. 17 & Quantitativo \\
\hline 4 & Item 33 (a) & Quantitativo/Qualitativo & 4 & Inciso $\mathrm{V}, \S 8^{\circ}$, Art. 17 & Qualitativo \\
\hline 5 & Item 33 (b) & Qualitativo & 5 & Inciso VI, $\S 8^{\circ}$, Art. 17 & Quantitativo/Qualitativo \\
\hline 6 & Item 36 (b) & Quantitativo/Qualitativo & 6 & Inciso VII, $\S 8^{\circ}$, Art. 17 & Qualitativo \\
\hline 7 & Item 36 (c) & Qualitativo & 7 & Inciso VIII, $\S 8^{\circ}$, Art. 17 & Quantitativo \\
\hline 8 & Item 37 (a) & Qualitativo & 8 & Inciso IX, $\S 8^{\circ}$, Art. 17 & Qualitativo \\
\hline 9 & Item 37 (b) & Qualitativo & 9 & Inciso $X, \S 8^{\circ}$, Art. 17 & Quantitativo/Qualitativo \\
\hline 10 & Item 38 (a) & Quantitativo/Qualitativo & 10 & Inciso XI, $\S 8^{\circ}$, Art. 17 & Qualitativo \\
\hline 11 & Item 38 (b) & Qualitativo & 11 & Inciso XII, $\S 8^{\circ}$, Art. 17 & Quantitativo/Qualitativo \\
\hline 12 & Item 40(a) & Quantitativo/Qualitativo & 12 & Inciso XIII (a), $\$ 8^{\circ}$, Art. 17 & Quantitativo/Qualitativo \\
\hline & & & 13 & Inciso XIII (b), § $8^{\circ}$, Art. 17 & Qualitativo \\
\hline & & & 14 & Inciso XIV,$\S 8^{\circ}$, Art. 17 & Qualitativo \\
\hline & & & 15 & Inciso XXI, $\S 8^{\circ}$, Art. 17 & Qualitativo \\
\hline & & & 16 & Art. 16 & Qualitativo \\
\hline
\end{tabular}

Fonte: Adaptado de CPC 40 (R1) e ICVM no 489/11

Após o procedimento de categorização, a análise de conteúdo foi estabelecida a partir da codificação e quantificação dos dados. Oliveira et al. (2003) relatam que é necessário codificar os dados coletados a fim de que os mesmos possam ser alocados à grupos relacionados com suas características, podendo ser tabelados e contados. A codificação foi realizada manualmente e demandou a observação dos critérios determinados pelo pesquisador que permitem analisar a qualidade das informações, conforme os tipos de informações listados no Quadro 2. 
Quadro 2 - Codificação dos dados

\begin{tabular}{|c|l|c|}
\hline $\begin{array}{c}\text { Tipos de } \\
\text { informações }\end{array}$ & \multicolumn{1}{|c|}{ Descrição } & $\begin{array}{c}\text { Códigos } \\
\text { atribuídos }\end{array}$ \\
\hline 1 & Não divulga critérios obrigatórios e não comunica o motivo para tal ausência. & 0 \\
\hline 2 & $\begin{array}{l}\text { Divulga que atende o critério exigido pela normatização, sem qualquer avaliação } \\
\text { quantitativa ou qualitativa. }\end{array}$ & 1 \\
\hline 3 & $\begin{array}{l}\text { a) Divulga critério exigido pela normatização apenas de forma quantitativa ou } \\
\text { apenas qualitativamente quando é exigido evidenciar os dois aspectos; ou, } \\
\text { b) Divulga parcialmente o critério. }\end{array}$ & 2 \\
\hline 4 & $\begin{array}{l}\text { a) Divulga o critério exigido pela normatização de forma quantitativa e } \\
\text { qualitativa (quando aplicável); ou, } \\
\text { b) Não divulga critérios obrigatórios, porém, comunica não a aplicação desta } \\
\text { obrigatoriedade e o motivo para tal ausência. }\end{array}$ & 3 \\
\hline
\end{tabular}

Fonte: Dados da pesquisa (2016)

O tipo 1 retrata a pior conjuntura em relação a divulgação das informações (ausência de informações), enquanto que o tipo 4 indica as situações em que há divulgação de informações completas, considerando plenamente as exigências normativas. Os tipos intermediários (2 e 3 ) retratam aspectos parciais do disclosure contábil, que podem ser mais próximos da ausência de informação (tipo 2) ou mais próximos da divulgação de informações completas (tipo 3). Esta sistemática permitiu quantificar cada um dos critérios normativos de evidenciação a partir da análise das notas explicativas, ao longo de 2012, 2013 e 2014, de cada FIDC que compôs a amostra.

Métodos quantitativos foram utilizados para estabelecer proporções e correlações entre as variáveis observadas, procurando por elementos que permitiram a comprovação das hipóteses defendidas (DENCKER; VIÁ, 2001). Para avaliar $\mathrm{H}_{1}$ foi aplicado Teste $t$ de Student sobre a média populacional a partir de uma amostra aleatória. A $\mathrm{H}_{2}$ foi verificada por meio do Teste $t$ com amostras pareadas, observando a variação ocorrida ao longo do tempo. $\mathrm{A}_{3}$ foi testada por meio de Teste $t$ com amostras independentes. A normalidade dos dados utilizados foi considerada a partir do tamanho da amostra $(n>30)$ e a homogeneidade das variâncias foi encontrada por meio do Teste Levene ( $p$-value >0,05). A $\mathrm{H}_{4}$ utilizou teste não paramétrico de Kruskal-Wallis, visto que, apesar de atender ao pressuposto de normalidade dos dados $(n>30)$, a homogeneidade das variâncias não foi constatada pelo Teste Levene $(p$-value $<0,05)$. Todos estes testes foram feitos no Software SPSS, versão 20.

\section{Análise dos Resultados}

Neste capítulo os elementos subjacentes as normas de contabilidade foram analisados, por meio de técnicas estatísticas, quanto a divulgação do risco de crédito pelos FIDCs.

\subsection{Análise do nível de atendimento dos requisitos normativos}

O estado da divulgação do risco de crédito foi determinado a partir da análise das notas explicativas dos FIDCs com a finalidade de identificar o nível de atendimento dos critérios normativos que tratam sobre a evidenciação destas informações. A média geral por ano do atendimento dos requisitos de evidenciação do CPC 40 (R1) foi de 30,11\% em 2013, de 32,21\% em 2013 e de 32,47\% em 2014. Ou seja, em média, um terço dos critérios normativos do CPC 40 (R1) relativos a divulgação do risco de crédito são atendidos pelos FIDCs. A média de atendimento dos critérios de divulgação da ICVM no 489/11 no ano de 2012 representou 44,37\%, em 2013 foi de $54,12 \%$ e em 2014 atendeu 58,38\%.

Ao avaliar a evidenciação que deve ser realizada pelos FIDCs e observar a divulgação que foi efetuada por meio das notas explicativas percebe-se que houve atendimento parcial dos 
regulamentos. Assim como defendido por Barth e Landsman (2010), Cheng, Dhaliwal e Neamtiu (2008) e Jackson (2010) quanto às securitizadoras no âmbito internacional, existe assimetria de informação quanto ao risco de crédito das operações dos FIDCs, visto que faltam informações públicas de aspectos essenciais deste tipo de risco que os investidores não podem ter acesso por outros meios.

Tabela 1 - Comparação entre a divulgação praticada e o nível esperado de divulgação pelos FIDCs em relação aos critérios contidos no CPC 40 (R1)

\begin{tabular}{|c|c|c|c|c|c|c|}
\hline \multirow{3}{*}{ Ano } & \multicolumn{6}{|c|}{ Valor de teste $=36$} \\
\hline & \multirow[t]{2}{*}{$\mathrm{t}$} & \multirow{2}{*}{$\begin{array}{l}\text { Grau de } \\
\text { liberdade }\end{array}$} & \multirow{2}{*}{$\begin{array}{c}\text { Sig. } \\
\text { (2-caudas) }\end{array}$} & \multirow[t]{2}{*}{ Diferença média } & \multicolumn{2}{|c|}{$\begin{array}{c}\text { Diferença com intervalo de } \\
\text { confiança de } 95 \%\end{array}$} \\
\hline & & & & & Inferior & Superior \\
\hline 2012 & $-76,526$ & 147 & 0,000 & $-25,16216$ & $-25,8120$ & $-24,5124$ \\
\hline 2013 & $-67,816$ & 147 & 0,000 & $-24,40541$ & $-25,1166$ & $-23,6942$ \\
\hline 2014 & $-68,658$ & 147 & 0,000 & $-24,31081$ & $-25,0106$ & $-23,6111$ \\
\hline
\end{tabular}

Fonte: Dados da pesquisa (2016).

A Tabela 1 demonstra a análise efetuada com o objetivo de verificar, estatisticamente, se existe diferença significativa entre o nível de divulgação que deveria existir (índice 36 em cada FIDC, devido a análise conter 12 critérios normativos em que cada um pode receber nota até 3), conforme prescrições do CPC 40 (R1), e o nível de divulgação encontrado nas notas explicativas dos FIDCs. O teste $t$ de Student para a amostra indica que, em todos os três períodos analisados, o $p$-value do teste é menor que 0,05 . Ou seja, considerando o intervalo de confiança de $95 \%$, a hipótese nula de igualdade é rejeitada. Isto permite considerar que a média da divulgação do risco de crédito realizada pelos FIDCs, em relação aos critérios presentes no CPC 40 (R1), é significativamente inferior ao nível de detalhamento exigido.

Tabela 2 - Comparação entre a divulgação praticada e o nível esperado de divulgação pelos FIDCs em relação aos critérios contidos na ICVM no 489/11

\begin{tabular}{|c|c|c|c|c|c|c|}
\hline \multirow{3}{*}{ Ano } & \multicolumn{6}{|c|}{ Valor de teste $=48$} \\
\hline & \multirow[t]{2}{*}{$\mathrm{t}$} & \multirow{2}{*}{$\begin{array}{l}\text { Grau de } \\
\text { liberdade }\end{array}$} & \multirow{2}{*}{$\begin{array}{c}\text { Sig. } \\
\text { (2-caudas) }\end{array}$} & \multirow[t]{2}{*}{ Diferença média } & \multicolumn{2}{|c|}{$\begin{array}{c}\text { Diferença com intervalo de } \\
\text { confiança de } 95 \%\end{array}$} \\
\hline & & & & & Inferior & Superior \\
\hline 2012 & $-43,387$ & 147 & 0,000 & $-26,70270$ & $-27,9190$ & $-25,4864$ \\
\hline 2013 & $-44,754$ & 147 & 0,000 & $-22,02027$ & $-22,9926$ & $-21,0479$ \\
\hline 2014 & $-43,542$ & 147 & 0,000 & $-19,99324$ & $-20,9007$ & $-19,0858$ \\
\hline
\end{tabular}

Fonte: Dados da pesquisa (2016)

O nível de evidenciação encontrado nas notas explicativas, considerando as exigências constantes na ICVM n ${ }^{\circ} 489 / 11$, foi avaliado a fim de identificar se existe diferença significativa entre a divulgação efetivamente realizada e a divulgação exigida, que, caso atendida integralmente, e resultaria no nível 48 (16 critérios x 3, que é a nota máxima). A Tabela 2 demonstra os resultados do Teste $t$ de Student, aplicado nos anos de 2012, 2013 e 2014, cujos $p$-values ficam abaixo de 0,05. Dentro do intervalo de confiança de $95 \%$, rejeita-se a hipótese nula de igualdade das médias, indicando que, empiricamente, a média do nível de divulgação do risco de crédito praticado pelos FIDCs, conforme critérios presentes na ICVM nº 489/11, é significativamente inferior ao exigido por esta norma.

Conforme os resultados apresentados nas Tabelas 1 e 2, não se rejeita Hipótese 1. Estatisticamente é identificado que os FIDCs atendem parcialmente aos requisitos normativos de evidenciação de informações sobre o risco de crédito, independentemente dos regulamentos aos quais estão submetidos. Estes resultados convergem com pesquisas internacionais e nacionais 
quanto à identificação do não cumprimento das normas contábeis de evidenciação do risco de crédito, confirmando os resultados encontrados por Amran et al. (2009), Domínguez e Gámez (2014), Lajili e Zeghal (2005), Linsley e Shrives (2006), Rajab e Handley-Schachler (2009), Othman e Ameer (2009), Pinto e Lemos (2013), Dantas et al. (2010) e Shinzato (2011). Verificase que a ausência de informações sobre risco é comum em diversas atividades e períodos, não se tratando de um evento isolado por setor ou condição temporal.

Ao identificar que os FIDCs atendem metade ou menos dos critérios de divulgação impostos pelos regulamentos contábeis, e que este patamar de divulgação é significativamente inferior ao esperado, é possível inferir que, normas de contabilidade exercem influência sobre as práticas das organizações. Entretanto, existem mais demandas com forças iguais ou superiores, ainda que informais, que coabitam o cenário da publicidade de informações das finanças estruturadas. A crise financeira desencadeada em 2007 apontou a necessidade da contabilidade assumir uma posição mais ativa no estabelecimento de segurança na securitização. Contudo, passada uma década de tal evento, parte da informação sobre riscos ainda permanece velada neste mercado.

Sob o constructo da Teoria da Informação assimétrica, todas as ações empregadas pelas organizações geram informações ao mercado e é necessário identificar como novas informações são geradas e disseminadas no mercado (STIGLITZ, 2000). Fica evidente que emitir novos regulamentos ou refinar a requisição de informação é uma importante contribuição com a securitização, mas, não é suficiente. Como o ato de não divulgar informações é uma forma de sinalização (SPENCE, 2002), os resultados apresentados sugerem que o enforcement das normas de contabilidade deve ser reforçado por meio de outros recursos a fim de subsidiar mais legitimidade e para que tais normas sejam efetivas.

Com a finalidade de analisar o nível de divulgação praticado pelos FIDCs ao longo do tempo de vigência das normas, buscou-se verificar se a média de evidenciação apresentou alterações durante o período abrangido por este estudo, conforme demonstrado na Tabela 3.

Tabela 3 - Comparação do atendimento dos critérios contidos no CPC 40 (R1) quanto ao ano de emissão das demonstrações contábeis

\begin{tabular}{|c|c|c|c|c|c|c|c|c|}
\hline \multirow{3}{*}{$\begin{array}{c}\text { Comparação de } \\
\text { pares }\end{array}$} & \multicolumn{5}{|c|}{ Diferenças pareadas } & & \multirow{3}{*}{$\begin{array}{l}\text { Grau de } \\
\text { liberdade }\end{array}$} & \multirow{3}{*}{$\begin{array}{c}\text { Sig. } \\
\text { (2-caudas) }\end{array}$} \\
\hline & \multirow[t]{2}{*}{ Média } & \multirow[t]{2}{*}{$\begin{array}{l}\text { Desvio } \\
\text { padrão }\end{array}$} & \multirow{2}{*}{$\begin{array}{l}\text { Erro } \\
\text { médio } \\
\text { padrão }\end{array}$} & \multicolumn{2}{|c|}{$\begin{array}{c}\text { Intervalo de } \\
\text { confiança de } 95 \%\end{array}$} & & & \\
\hline & & & & Inferior & Superior & & & \\
\hline $\begin{array}{ll}\text { Par } 1 \quad 2012-2013 \\
\end{array}$ & $-0,7567$ & 2,52773 & 0,20778 & $-1,16737$ & $-0,34614$ & $-3,642$ & 147 & 0,000 \\
\hline Par $2 \quad 2013-2014$ & $-0,0945$ & 2,00794 & 0,16505 & $-0,42077$ & 0,23159 & $-0,573$ & 147 & 0,567 \\
\hline
\end{tabular}

Fonte: Dados da pesquisa (2016)

A média de divulgação do risco de crédito pelos FIDCs, considerando as exigências emanadas pelo CPC 40 (R1), foi avaliada por meio do Teste $t$ de Student para amostras pareadas. A avaliação comparou o índice de evidenciação praticado em 2013 em relação à 2012, e a evidenciação encontrada em 2014 comparada à 2013. O primeiro par de comparação de médias (2012-2013) apresentou $p$-value menor que 0,05 , permitindo inferir, com intervalo de confiança de $95 \%$, que a hipótese nula de igualdade deve ser rejeitada. Isto leva a compreender que o nível de divulgação de 2013 é significativamente maior em relação à 2012.

Quanto a análise do segundo par (2013-2014), encontrou-se $p$-value maior que 0,05 , cujo resultado não permite rejeitar a hipótese de igualdade de médias, com intervalo de confiança de 95\%. Revela assim, que, apesar de se verificar que quantitativamente o nível de evidenciação do risco de crédito pelos FIDCs em 2014 é maior em relação à 2013, esta diferença não é significativa. Sob a perspectiva do CPC 40 (R1), os resultados apresentados na Tabela 3 suportam parcialmente a Hipótese 2. 
Elementos subjacentes aos regulamentos e a divulgação do risco de crédito em fundos de investimento em direitos creditórios

\begin{tabular}{|c|c|c|c|c|c|c|c|c|}
\hline \multirow{3}{*}{$\begin{array}{c}\text { Comparação de } \\
\text { pares }\end{array}$} & \multicolumn{5}{|c|}{ Diferenças pareadas } & \multirow{3}{*}{$\mathrm{t}$} & \multirow{3}{*}{$\begin{array}{l}\text { Grau de } \\
\text { liberdade }\end{array}$} & \multirow{3}{*}{$\begin{array}{c}\text { Sig. } \\
\text { (2-caudas) }\end{array}$} \\
\hline & \multirow[t]{2}{*}{ Média } & \multirow[t]{2}{*}{$\begin{array}{l}\text { Desvio } \\
\text { padrão }\end{array}$} & \multirow{2}{*}{$\begin{array}{l}\text { Erro } \\
\text { médio } \\
\text { padrão }\end{array}$} & \multicolumn{2}{|c|}{$\begin{array}{c}\text { Intervalo de } \\
\text { confiança de } 95 \% \\
\end{array}$} & & & \\
\hline & & & & Inferior & Superior & & & \\
\hline Par 1 2012-2013 & $-4,6824$ & 5,73097 & 0,47108 & $-5,61340$ & $-3,75146$ & $-9,940$ & 147 & 0,000 \\
\hline Par $2 \quad 2013-2014$ & $-2,0270$ & 3,31549 & 0,27253 & $-2,56561$ & $-1,48844$ & $-7,438$ & 147 & 0,000 \\
\hline
\end{tabular}

Fonte: Dados da pesquisa (2016)

A Tabela 4 demonstra Teste $t$ de Student para amostras pareadas que comparou a média de divulgação do risco de crédito em função do tempo, considerando os critérios normativos da ICVM n 489/11. Para isso foram comparados os índices de divulgação de 2013 em relação à 2012, assim como os índices de 2014 quanto à 2013. Os resultados encontrados demonstram $p$-value menor que 0,05 . Verifica-se, portanto, que, dentro do intervalo de confiança de $95 \%$, rejeita-se a hipótese nula de igualdade para as duas comparações. Isto permite identificar que, o índice médio de divulgação do risco de crédito pelos FIDCs, considerando os critérios presentes na ICVM n ${ }^{\circ}$ 489/11, é maior, quantitativamente, em 2013 em relação à 2012 e em 2014 relacionado à 2013, e que, estatisticamente, foram encontradas evidências de que esta diferença é significativa. Por meio destes resultados não se rejeita a Hipótese 2, considerando apenas os requisitos de divulgação da ICVM no 489/11.

Verifica-se que os FIDCs melhoraram significativamente o nível de divulgação do risco de crédito conforme prescrição da ICVM no 489/11 ao longo do período analisado, cujo resultado é coerente com as pesquisas de Rajab e Handley-Schachler (2009) e Dantas et al. (2010). Porém, o mesmo não ocorreu quanto aos critérios normativos do CPC 40 (R1) na comparação de períodos mais recentes. Conforme Stiglitz (2000), o ponto de partida sobre o estudo da economia da informação deve ser a investigação sobre como a economia adapta-se a novas informações e cria novos conhecimentos e como esse conhecimento é disseminado, absorvido e utilizado em toda a economia. Sob este pressuposto, é possível compreender a emissão e a revisão das normas de contabilidade como dispositivos que performam o conhecimento público sobre as organizações.

Ao encontrar que os níveis de divulgação, em geral, aumentaram ao longo do período avaliado, é possível defender que os FIDCs evoluíram quanto ao engajamento na adesão aos regulamentos, e, consequentemente, às demandas do mercado. Contudo, considerando que a adesão aos requisitos normativos permaneceu baixa, é possível reconhecer que a economia da informação relativa ao risco crédito da securitização brasileira permanece contaminada por restrições informativas que podem ser consideradas anomalias do processo de disclosure que foi estruturado pela emissão de nova regulamentação contábil.

\subsection{Análise do nível de divulgação quanto às características dos critérios normativos}

A Hipótese 3 deste estudo descreve que o nível de atendimento dos critérios de divulgação do risco de crédito definidos pela ICVM no 489/11 é maior em relação ao atendimento dos critérios do CPC 40 (R1). Com a finalidade de testar esta hipótese, foi aplicado o Teste $t$ de Student com amostras independentes, considerando individualmente cada período abrangido pelo estudo, cujos resultados estão demonstrados na Tabela 5.

Os resultados mostram que o $p$-value do teste é inferior a 0,05 , em todos os três períodos, permitindo rejeitar a hipótese nula de igualdade de médias, com intervalo de confiança de $95 \%$. Estes resultados suportam $\mathrm{H}_{3}$ ao mostrar que o nível de atendimento dos critérios de divulgação do risco de crédito definidos pela ICVM nº 489/11 é maior, significativamente, em relação ao atendimento dos critérios do CPC 40 (R1). Tal resultado converge com os achados da pesquisa de Garcia, Fadel e Moraes (2015) e confirma os resultados de Rajab e Handley-Schachler (2009) em 
relação à dificuldade de atender as normas genéricas de evidenciação do risco de crédito. Aflui ainda com a posição defendida por Cerbioni, Fabrizi e Parbonetti (2015) que reivindicam o desenvolvimento de normas contábeis específicas para a securitização, considerando as particularidades das entidades e das atividades deste segmento.

Tabela 5 - Comparação do atendimento dos critérios de divulgação por regulamentos

\begin{tabular}{|c|c|c|c|c|c|c|c|c|c|c|}
\hline & \multicolumn{2}{|c|}{ Teste Levene } & \multicolumn{7}{|c|}{ Teste $t$ de igualdade de médias } \\
\hline & & \multirow[t]{2}{*}{$\mathrm{F}$} & \multirow[t]{2}{*}{ Sig. } & \multirow[t]{2}{*}{$\mathrm{t}$} & \multirow[t]{2}{*}{ df } & \multirow{2}{*}{$\begin{array}{c}\text { Sig. } \\
(2- \\
\text { caudas) }\end{array}$} & \multirow{2}{*}{$\begin{array}{l}\text { Diferença } \\
\text { média }\end{array}$} & \multirow{2}{*}{$\begin{array}{c}\text { Erro } \\
\text { médio } \\
\text { padrão }\end{array}$} & \multicolumn{2}{|c|}{$\begin{array}{c}\text { Intervalo de } \\
\text { confiança de } 95 \%\end{array}$} \\
\hline & & & & & & & & & Inferior & Inferior \\
\hline \multirow{2}{*}{2012} & $\begin{array}{l}\text { Igualdade de } \\
\text { variâncias } \\
\text { assumidas }\end{array}$ & 62,347 & 0,000 & 14,990 & 294 & 0,000 & 10,4595 & 0,6978 & 9,0862 & 11,8327 \\
\hline & $\begin{array}{c}\text { Igualdade de } \\
\text { variâncias não } \\
\text { assumidas } \\
\end{array}$ & & & 14,990 & 224,592 & 0,000 & 10,4595 & 0,6978 & 9,0844 & 11,8345 \\
\hline \multirow{2}{*}{2013} & $\begin{array}{l}\text { Igualdade de } \\
\text { variâncias } \\
\text { assumidas }\end{array}$ & 21,076 & 0,000 & 23,598 & 294 & 0,000 & 14,38514 & 0,6096 & 13,185 & 15,5849 \\
\hline & $\begin{array}{c}\text { Igualdade de } \\
\text { variâncias não } \\
\text { assumidas }\end{array}$ & & & 23,598 & 269,285 & 0,000 & 14,38514 & 0,6096 & 13,185 & 15,5853 \\
\hline \multirow{2}{*}{2014} & $\begin{array}{l}\text { Igualdade de } \\
\text { variâncias } \\
\text { assumidas } \\
\end{array}$ & 13,881 & 0,000 & 28,141 & 294 & 0,000 & 16,31757 & 0,5798 & 15,177 & 17,4587 \\
\hline & $\begin{array}{c}\text { Igualdade de } \\
\text { variâncias não } \\
\text { assumidas }\end{array}$ & & & 28,141 & 276,157 & 0,000 & 16,31757 & 0,5798 & 15,176 & 17,4590 \\
\hline
\end{tabular}

Fonte: Dados da pesquisa (2016)

Stiglitz (2000) defende como pressuposto da Teoria da Informação Assimétrica que sempre permanece algum grau de assimetria cuja extensão é afetada por ações de empresas e indivíduos. Por meio da presente pesquisa é possível verificar que a assimetria de informação é mais pronunciada quanto aos requisitos do CPC 40 (R1), visto que os FIDCs empregam maior atenção à ICVM n ${ }^{\circ} 489 / 11$. Este resultado indica que a relação entre os FIDCs e as normas contábeis se estabelece distintamente, considerando o órgão emissor. Esta análise corrobora o pressuposto de que a economia da informação apresenta explicações de fenômenos e instituições relacionados com a informação imperfeita (STIGLITZ, 2000).

Outra característica analisada por este estudo considera os critérios normativos de evidenciação do risco de crédito quanto aos aspectos que possuem. Isto permitiu classificar cada critério normativo em qualitativo, quantitativo e qualitativo/quantitativo, conforme demonstrado no Quadro 1. A Hipótese 4 desta pesquisa defende que o nível de divulgação do risco de crédito é maior em critérios normativos qualitativos em relação aos aspectos quantitativos de evidenciação. Aplicou-se o Teste de Kruskal-Wallis com o objetivo de testar esta hipótese, cujos resultados são demonstrados na Tabela 6.

Por meio da análise das médias de divulgação, verifica-se que os critérios de evidenciação quantitativos possuem índice maior em relação aos outros dois critérios. Na sequência, encontrase o segundo maior índice dado pelos critérios qualitativo/quantitativo e o menor índice foi atribuído aos critérios com aspecto qualitativo. Por meio do Teste de Kruskal-Wallis as amostras foram testadas dentro do intervalo de confiança de $95 \%$, encontrando $p$-value menor que 0,05 e, com isso, rejeitou-se a hipótese nula. Isto representa que as amostras provêm de populações diferentes, contudo, como a média de divulgação de critérios quantitativos é maior em relação aos demais critérios, os resultados levam a rejeitar a Hipótese 4. 
Elementos subjacentes aos regulamentos e a divulgação do risco de crédito em fundos de investimento em direitos creditórios

Tabela 6 - Comparação do atendimento normativo quanto aos critérios de evidenciação

\begin{tabular}{l|l|c|c}
\hline & Critérios & $\mathrm{N}$ & Média \\
\hline \multirow{4}{*}{$\begin{array}{l}\text { Divulgação por } \\
\text { critérios }\end{array}$} & Qualitativo & 148 & 126,94 \\
\cline { 2 - 4 } & Quantitativo & 148 & 349,69 \\
\cline { 2 - 4 } & Qualitativo/ Quantitativo & 148 & 190,86 \\
\cline { 2 - 4 } & Total Qui-Quadrado & 444 & 236,789 \\
\hline \multicolumn{1}{c|}{ df } & 2 \\
\hline \multicolumn{1}{c|}{ Sig. } & 0,000 \\
\hline
\end{tabular}

Fonte: Dados da pesquisa (2016)

O resultado apresentado na Tabela 6 mostra diferença significativa na divulgação do risco crédito quanto aos aspectos dos critérios normativos, confirmando que o tipo de informação requerida pelas normas pode ser atendido de forma diferente, dependendo do aspecto que possui. Contudo, diferentemente de pesquisas precedentes, o nível de divulgação do risco de crédito em FIDCs é menor em critérios normativos qualitativos em relação aos aspectos quantitativos. Estes achados chamam atenção, pois, divergem dos resultados das pesquisas de Lajili e Zéghal (2005), Linsley e Shrives (2006), Othman e Ameer (2009) e Silva, Machado e Hein (2013), que destacam os aspectos quantitativos em menor nível de evidenciação em relação aos qualitativos.

Apesar de os resultados não suportarem $\mathrm{H}_{4}$, identifica-se que a assimetria informacional está presente tanto em critérios normativos com aspectos quantitativos quanto qualitativos. Esta observação é coerente com Dantas et al. (2005) e Valente, (2014) que em suas pesquisas já haviam destacado que os regulamentos contábeis não são cumpridos em sua totalidade, tanto em âmbito quantitativo, como qualitativo.

A presente pesquisa destaca que os FIDCs preferem relacionar valores de investimentos e possíveis perdas ao invés de identificar os fatos que podem gerar ou que geraram perdas. Descaracteriza, portanto, o enquadramento da informação como relevante, considerando o pressuposto da Teoria da Informação Assimétrica de que a informação deve contemplar diferentes abordagens qualitativas e quantitativas (STIGLITZ, 2000).

Os resultados opostos ao da hipótese suscita que os FIDCs podem gerenciar a divulgação da informação com a finalidade de não expor ao público as características concretas dos títulos emitidos ao mercado, visto que a informação qualitativa do risco de crédito é mais fácil de ser cunhada em relação à quantitativa (DOBLER, 2008). Sob esta perspectiva, a adesão fracionada às normas de contabilidade pelos FIDCs pode estar ocorrendo em prol da opacidade das informações que permite a manutenção da estrutura sem alarmar os agentes de mercado.

\section{Considerações Finais}

O objetivo do estudo foi analisar a influência de elementos subjacentes à regulação contábil na evidenciação do risco de crédito praticada pelos FIDCs. Ao analisar as notas explicativas dos FIDCs, nos anos de 2012, 2013 e 2014, percebe-se que há atendimento parcial dos regulamentos e que a evidenciação praticada difere significativamente da evidenciação requerida pelas normas. Os achados sugerem que elementos subjacentes à regulação contábil, como a especificidade da norma, o tempo de vigência e o aspecto da informação, influenciam a evidenciação do risco de crédito em títulos de FIDCs.

Compreende-se, por meio dos resultados encontrados, que a ausência de informações completas sobre o risco de crédito pode ser fonte de seleção adversa na securitização brasileira. Isso indica que, mesmo após as discussões devido a relação entre a crise dos subprimes e a securitização, este segmento ainda é acometido por graves falhas de assimetria informacional. Parte desta assimetria pode ser tratada como uma situação normal, dado os pressupostos da Teoria da Informação Assimétrica. Spence (2002) alega que no mercado financeiro não se encontram 
informações completas, sendo preciso emitir sinais de que a entidade oferece oportunidades compatíveis aos interesses dos investidores. Entretanto, Stiglitz (2000) relata que, apesar das empresas emitirem sinalização das suas condições, estes sinais não são suficientes ao mercado.

Existe o argumento de que a seleção adversa é intrínseca a securitização, visto que o originador do crédito sempre possui mais conhecimento sobre os riscos de crédito dos ativos securitizados que as securitizadoras (AGARWAL; CHANG; YAVAS, 2012). Porém, esta alegação não pode ser naturalizada, pois, o desequilíbrio do sistema financeiro tem um impacto generalizado na sociedade. A crise dos subprimes é uma demonstração do potencial da securitização em alavancar a movimentação financeira, assim como desestabilizar economias globais. Portanto, as securitizadoras devem buscar meios para fomentar equilíbrio ao mercado e seus agentes, e, por isso, são responsáveis pela qualidade das informações acerca dos investimentos que disponibilizam.

Em busca de equilíbrio e segurança, os agentes de mercado desenvolvem constantemente novas formas de incentivar a divulgação das informações que necessitam. Quanto à atuação dos FIDCs, observa-se que, apesar de serem aplicáveis diversos métodos de sinalização aos seus investidores (subordinação, covenants, reserva de caixa, colaterização etc.), a informação, clara e objetiva, ainda é requerida como recurso de apoio decisório. Tal necessidade justifica a presença de regulamentos específicos, como a ICVM n ${ }^{\circ}$ 489/11, e pelo esforço na explicação de uso desta norma pelo órgão responsável por meio da Nota Explicativa ICVM nº 489/11. Segundo Stiglitz (2000), sem a interferência de órgãos de controle, a imperfeição de mercado seria majorada e causaria ainda mais riscos.

Os resultados da pesquisa indicaram ausência de divulgação de uma parcela de informações a respeito do risco de crédito pelos FIDCs, principalmente em relação ao CPC 40 (R1). Considerando que os pronunciamentos contábeis têm o objetivo de determinar a divulgação de informações essenciais aos seus usuários, o cumprimento parcial desta divulgação fomenta a permanência da assimetria de informação. Em contraponto, observa-se maior nível de atendimento da ICVM no 489/11. Com isso, verifica-se que, apesar de não haver pleno cumprimento da ICVM $\mathrm{n}^{\circ} 489 / 11$ quanto à divulgação do risco de crédito, pode-se identificar que esta norma atua como elemento dissipador da assimetria de informação em maior potencial em comparação ao CPC 40 (R1). Isto porque é mais acatada a cada ano que passa e cuja observação e atendimento é superior às normas gerais de divulgação de informações defendidas pelo CPC 40 (R1).

Ao demonstrar que os regulamentos da CVM são mais respeitados, a presente pesquisa apresenta contribuição acerca do reconhecimento da influência dos órgãos emissores de normas e desperta atenção para o fato de uma norma considerada complementar obter maior adesão em relação ao regulamento principal. Esta ocorrência pode estar ligada a algumas distinções entre as normas e os órgãos. Uma delas refere-a ao nível de especificidade da ICVM nº 489/11 em relação às atividades de securitização, proporcionando melhor compreensão e aplicação. Outra possibilidade é o poder de polícia exercido pela CVM, ou seja, além de emitir regulamentos, também atua fiscalizando e aplicando sanções às entidades que não cumprem os regulamentos. $\mathrm{A}$ fiscalização não é uma incumbência do CPC, logo, a dissociação entre o órgão emissor de normas e o órgão fiscalizador sugere possíveis ineficiências ao enforcement atribuído a esta conjunção. Por fim, o fato da CVM estar diretamente ligada a regulação do mercado de capitais pode elevar seu status de legitimidade perante os fundos, que são atuantes e dependentes deste ambiente.

Os achados geram questionamentos sobre a necessidade de uma atuação mais eficaz do Conselho Federal de Contabilidade junto às entidades quanto ao cumprimento de suas normas. Passada uma década da convergência às normas internacionais e superadas as dificuldades iniciais de adaptação, somadas as diversas pesquisas acadêmicas que enfatizam problemas na divulgação de informações ao mercado, em variados segmentos, pouco se sabe sobre a postura dos órgãos contábeis reguladores e fiscalizadores sobre este contexto. Ou seja, se a assimetria presente tanto 
na securitização quanto em outras atividades é vista com normalidade pelos órgãos contábeis ou se existe dificuldade em desenvolver formas de contornar tal situação no contexto brasileiro.

Outra contribuição oferecida pela pesquisa foi demonstrar que os critérios normativos com aspectos quantitativos obtiveram nível de atendimento superior aos critérios qualitativos e quantitativos e qualitativos concomitante e que a diferença é estatisticamente relevante. $\mathrm{O}$ baixo nível de informações qualitativas mostra que os FIDCs não efetuam o detalhamento das situações que envolvem os ativos securitizados, potencializando o efeito da assimetria de informação quanto aos fatos geradores do risco de crédito. Este resultado indica que o formato da informação requerida pelos regulamentos tem influência sobre a decisão de ser atendida e que pode estar ocorrendo um gerenciamento de quais informações os fundos permitem divulgar. Sob a perspectiva da Teoria da Informação Assimétrica, a fim de que os investidores sejam providos com informações, os critérios normativos qualitativos, em especial, precisam ser atendidos de forma que haja informações objetivas e claras efetivamente. Os órgãos emissores de normas contábeis devem considerar esta limitação ao desenvolver instrumentos regulatórios e buscar meios para dissipar tais entraves da divulgação compulsória.

Os achados da pesquisa, de forma geral, contribuem com o conhecimento de que existe um esforço dos órgãos reguladores de contabilidade em expandir a divulgação do risco de crédito dos FIDCs. Contudo, a baixa adesão das normas e a possível seleção das informações que se permite divulgar pelos fundos indica que elementos informais também têm atuado como determinantes da publicidade do risco de crédito da securitização. Assim, este segmento continua envolto pelas mesmas falhas de mercado que já abalaram mercados financeiros. Em vista disso, o enforcement das normas de contabilidade, representado pelos órgãos fiscalizadores, precisa passar por uma discussão pública sobre meios de aprimorar suas funções. Esta adaptação é prevista por Stiglitz (2000) que condiciona a Teoria da Assimetria Informacional com a necessidade de aperfeiçoar os meios e formatos que a informação é disseminada.

Enquanto limitação da pesquisa, é destacado o espaço de tempo de aplicação das normas que regulamentam a divulgação de informação sobre o risco de crédito das operações realizadas pelos FIDCs. A existência de demais forças não identificadas que influenciam a divulgação de informações, e, consequentemente, a adesão às normas de contabilidade, também são limitações das análises. Como sugestão para futuras pesquisas, é indicada a complementação deste estudo com a investigação de outros possíveis determinantes do nível de divulgação de informações sobre o risco de crédito em FIDCs, tanto subjacentes à regulamentação, como externos às normas contábeis e relacionadas aos fundos. Também sugere-se investigar a percepção dos representantes de órgãos contábeis sobre a assimetria de informação que prevalece no mercado e como as atividades de fiscalização tem atuado dentro deste campo.

\section{Referências}

ABRAHAM, Santhosh; COX, Paul. Analysing the determinants of narrative risk information in UK FTSE 100 annual reports. The British Accounting Review, v. 39, n. 3, p. 227-248, 2007. DOI: https://doi.org/10.1016/j.bar.2007.06.002

AKERLOF, George A. The market for" lemons": Quality uncertainty and the market mechanism. The Quarterly Journal of Economics, v. 84, n. 3, p. 488-500, 1970. DOI: https://www.jstor.org/10.2307/1879431

AMRAN, Azlan; BIN, Abdul Manaf Rosli; HASSAN, Bin Che Haat Mohd. Risk reporting: An exploratory study on risk management disclosure in Malaysian annual reports. Managerial Auditing Journal, v. 24, n. 1, p. 39-57, 2009. DOI: https://doi.org/10.1108/02686900910919893 
AGARWAL, Sumit; CHANG, Yan; YAVAS, Abdullah. Adverse selection in mortgage securitization. Journal of Financial Economics, v. 105, n. 3, p. 640-660, 2012. DOI: https://doi.org/10.1016/j.jfineco.2012.05.004

BARDIN, Laurence. Análise de conteúdo. 6. ed. Lisboa: Edições 70, 2006.

BARTH, Mary E.; LANDSMAN, Wayne R. How did financial reporting contribute to the financial crisis?. European Accounting Review, v. 19, n. 3, p. 399-423, 2010. DOI: https://doi.org/10.1080/09638180.2010.498619

BROWN, Robert W. Financial reform and the subsidization of sophisticated investors' ignorance in securitization markets. Journal of Law and Business, v. 7, p. 105, 2010.

CAMARA, Gilberto Ataide; GALDI, Fernando Caio. Securitização como mecanismo de gerenciamento de resultados em bancos brasileiros. Revista de Contabilidade e Organizações, v. 7, n. 18, p. 14-24, 2013. DOI: https://doi.org/10.11606/rco.v7i18.55610

CERBIONI, Fabrizio; FABRIZI, Michele; PARBONETTI, Antonio. Securitizations and the financial crisis: Is accounting the missing link? Accounting Forum, v. 39, n. 3, p. 155-175, 2015. DOI: https://doi.org/10.1016/j.accfor.2014.05.001

CHEN, Weitzu; LIU, Chi-Chun; RYAN, Stephen G. Characteristics of securitizations that determine issuers' retention of the risks of the securitized assets. The Accounting Review, v. 83, n. 5, p. 1181-1215, 2008. DOI: https://doi.org/10.2308/accr.2008.83.5.1181

CHENG, Mei; DHALIWAL, Dan; NEAMTIU, Monica. Banks' asset securitization and information opacity. Working Paper, The University of Arizona, 2008.

COELHO, Antonio Carlos Dias; BORELLI, Marcial Tadeu. Securitização. In: LIMA, Iran Siqueira; LIMA, Gerlando Augusto Sampaio Franco; PIMENTEL, Renê Coppe. (Ed.). Curso de mercado financeiro. 2. ed. São Paulo: Atlas, 2012. cap. 8. p. 131-162.

COMISSÃO DE VALORES MOBILIÁRIOS. Instrução CVM nº 489, de 14 de janeiro de 2011. Recuperado em 16 de maio de 2015, de http://www.cvm.gov.br.

COMISSÃO DE VALORES MOBILIÁRIOS. Retenção de risco na securitização: um estudo a partir da metodologia de análise de impacto regulatório. Assessoria de Análise e Pesquisa. 2014. Disponível em:

http://www.cvm.gov.br/export/sites/cvm/menu/acesso_informacao/serieshist/estudos/anexos/AI R_retencao-de-riscos.pdf. Acesso em: 25 abril 2015.

COMITÊ DE PRONUNCIAMENTOS CONTÁBEIS. CPC 40 (R1), de 30 de agosto de 2012. Instrumentos financeiros: evidenciação. 2012.

DANTAS, J. A.; ZENDERSKY, H. C.; SANTOS, S. C.; NIYAMA, J. K. A dualidade entre os benefícios do disclosure e a relutância das organizações em aumentar o grau de evidenciação. Revista Economia \& Gestão, v. 5, n. 11, p. 56-76, 2005.

DANTAS, José Alves; RODRIGUES, Fernanda Fernandes; RODRIGUES, Jomar Miranda; CAPELLETTO, Lucio Rodrigues. Determinantes do grau de evidenciação de risco de crédito 
pelos bancos brasileiros. Revista Contabilidade e Finanças, v. 21, n. 52, p. 1-27, 2010. DOI: https://doi.org/10.1590/S1519-70772010000100002

DENCKER, Ada de Freitas Maneti; VIÁ, Sarah Chucid. Pesquisa empírica em ciências humanas: Com ênfase em comunicação. São Paulo: Futura, 2001.

DOBLER, Michael. Incentives for risk reporting - A discretionary disclosure and cheap talk approach. The International Journal of Accounting, v. 43, n. 2, p. 184-206, 2008. DOI: https://doi.org/10.1016/j.intacc.2008.04.005

DOMÍNGUEZ, Luis Rodríguez; GÁMEZ, Ligia Carolina Noguera. Corporate reporting on risks: Evidence from Spanish companies. Revista de Contabilidad, v. 17, n. 2, p. 116-129, 2014. DOI: https://doi.org/10.1016/j.rcsar.2013.10.002

FAVERO JUNIOR, Osvaldo Zanetti. Securitização de ativos e transferência de risco: Evidências do mercado de capitais brasileiro. 2014. 195 f. Dissertação (Mestrado em Contabilidade e Controladoria) - Faculdade de Economia, Administração e Contabilidade, Universidade de São Paulo, São Paulo, 2014.

FERABOLLI, Cristina. Fatores de influência à securitização bancária no Brasil. 2014. 91 f. Dissertação (Mestrado em Ciências Contábeis) - Universidade do Vale do Rio dos Sinos, São Leopoldo, 2014.

FERNANDES, Mauricio Palmada; SHENG, Hsia Hua; LORA, Mayra Ivanoff. Securitização, rating de crédito e características dos emissores. Brazilian Business Review, v. 11, n. 6, p. 1-22, 2014. DOI: https://doi.org/10.15728/bbr.2014.11.6.1

GARCIA, Evelini Lauri Morri; FADEL, Mayra Orlandi; MORAES, Romildo de Oliveira. Análise da influência da estrutura das cotas de fundos de investimento em direitos creditórios na evidenciação do risco de crédito. In: CONGRESSO DA ASSOCIAÇÃO NACIONAL DE PROGRAMAS DE PÓS-GRADUAÇÃO EM CIÊNCIAS CONTÁBEIS, 14., 2015, Curitiba. Anais... Curitiba: ANPCONT, 2015.

GIL, Antonio Carlos. Como elaborar projetos de pesquisa. 5. ed. São Paulo: Atlas, 2010

GORTON, Gary B.; SOULELES, Nicholas S. Special purpose vehicles and securitization. In: The risks of financial institutions. University of Chicago Press, p. 549-602, 2007.

HEALY, Paul M.; PALEPU, Krishna G. Information asymmetry, corporate disclosure, and the capital markets: A review of the empirical disclosure literature. Journal of Accounting and Economics, v. 31, n. 1, p. 405-440, 2001. DOI: https://doi.org/10.1016/S0165-4101(01)00018-0

LAJILI, Kaouthar; ZÉGHAL, Daniel. A content analysis of risk management disclosures in Canadian annual reports. Canadian Journal of Administrative Sciences, v. 22, n. 2, p. 125 142, 2005. DOI: https://doi.org/10.1111/j.1936-4490.2005.tb00714.x

LEUZ, Christian; VERRECCHIA, Robert E. The economic consequences of increased disclosure. Journal of Accounting Research, p. 91-124, 2000. DOI: https://www.jstor.org/ $10.2307 / 2672910$ 
LINSLEY, Philip M.; SHRIVES, Philip J. Risk reporting: A study of risk disclosures in the annual reports of UK companies. The British Accounting Review, v. 38, n. 4, p. 387-404, 2006. DOI: https://doi.org/10.1016/j.bar.2006.05.002

MAIA, Henrique Araujo; FORMIGONI, Henrique; SILVA, Adilson Aderito da. Empresas de auditoria e o compliance com o nível de evidenciação obrigatório durante o processo de convergência às normas internacionais de contabilidade no Brasil. Revista Brasileira de Gestão de Negócios, v. 14, n. 44, p. 335-352, 2012. DOI: https://doi.org/10.7819/rbgn.v14i44.1047

MARTINS, Gilberto de Andrade; THEÓPHILO, Carlos Renato. Metodologia da investigação científica para ciências sociais aplicadas. 2. ed. São Paulo: Atlas, 2009

MICHALAK, Tobias C.; UHDE, André. Credit risk securitization and bank soundness in Europe. The Quarterly Review of Economics and Finance, v. 52, n. 3, p. 272-285, 2012. DOI: https://doi.org/10.1016/j.qref.2012.04.008

MILGROM, Paul R. Good news and bad news: Representation theorems and applications. The Bell Journal of Economics, v. 12, n. 2, p. 380-391, 1981. DOI:

https://www.jstor.org/10.2307/3003562

OLIVEIRA, Antonio Benedito Silva et al. Métodos e técnicas de pesquisa em contabilidade. São Paulo: Saraiva, 2003.

OLIVEIRA, Jonas; RODRIGUES, Lúcia Lima; CRAIG, Russell. Risk-related disclosures by non-finance companies: Portuguese practices and disclosure characteristics. Managerial Auditing Journal, v. 26, n. 9, p. 817-839, 2011. DOI:

https://doi.org/10.1108/02686901111171466

OTHMAN, Radiah; AMEER, Rashid. Market risk disclosure: Evidence from Malaysian listed firms. Journal of Financial Regulation and Compliance, v. 17, n. 1, p. 57-69, 2009. DOI: https://doi.org/10.1108/13581980910934045

PINHEIRO, Fernando Antonio Perrone. Securitização de recebíveis - uma análise dos riscos inerentes. 2008. 186 f. Dissertação (Mestrado em Administração) - Faculdade de Economia, Administração e Contabilidade, Universidade de São Paulo, São Paulo, 2008.

PINTO, C. R. A. A.; LEMOS, K. C. M. R. Fatores Determinantes da Divulgação de Informação sobre o Risco de Liquidez: Evidência empírica no sistema financeiro português.

In: CONGRESSO INTERNACIONAL DE CONTABILIDADE E AUDITORIA, 14., 2013, Lisboa. Anais... Lisboa: ISCA, 2013.

RAJAB, Bassam; HANDLEY-SCHACHLER, Morrison. Corporate risk disclosure by UK firms: Trends and determinants. World Review of Entrepreneurship, Management and Sustainable Development, v. 5, n. 3, p. 224-243, 2009. DOI:

https://doi.org/10.1504/WREMSD.2009.026801

SCHWARCZ, Steven L. The future of securitization. Connecticut Law Review, v. 41, n. 4, p. 1313-1325, 2009. 
SHINZATO, Julio Mituo. O uso de instrumentos financeiros e o nível de evidenciação qualitativa e quantitativa nas demonstrações contábeis de empresas não financeiras, no contexto das IFRS. 2011. 149 f. Dissertação (Mestrado em Ciências Contábeis e Atuariais) Pontifícia Universidade Católica de São Paulo, São Paulo, 2011.

SILVA, Tarcísio Pedro da; MACHADO, Débora Gomes; HEIN, Nelson. Análise exploratória da evidenciação da natureza e extensão dos riscos decorrentes de instrumentos financeiros nas notas explicativas de empresas listadas na BMeFBovespa. ConTexto, v. 13, n. 24, p. 37-49, 2013.

SPENCE, Michael. Signaling in retrospect and the informational structure of markets. The American Economic Review, v. 92, n. 3, p. 434-459, 2002. DOI: 10.1257/00028280260136200

STIGLITZ, Joseph E. Information and the change in the paradigm in economics. The American Economic Review, v. 92, n. 3, p. 460-501, 2002. DOI: 10.1257/00028280260136363

STIGLITZ, Joseph E. The contributions of the economics of information to twentieth century economics. The Quarterly Journal of Economics, v. 115, n. 4, p. 1441-1478, 2000. DOI: https://doi.org/10.1162/003355300555015

VERRECCHIA, Robert E. Essays on disclosure. Journal of Accounting and Economics, v. 32, n. 1, p. 97-180, 2001. DOI: https://doi.org/10.1016/S0165-4101(01)00025-8

* Uma versão preprint do artigo foi apresentada no XLI Encontro da ANPAD - EnANPAD em São Paulo, 2017.

APÊNDICE

\begin{tabular}{|c|c|l|}
\hline \multicolumn{2}{|c|}{ CPC 40 (R1) } \\
\hline 1 & Item 8 & O valor contábil de cada categoria de ativo financeiro \\
\hline 2 & Item 15 & $\begin{array}{l}\text { (a) o valor justo da garantia possuída; (b) o valor justo de qualquer garantia vendida } \\
\text { ou renovada, e se a entidade tiver obrigação de devolvê-la; e (c) os termos e as } \\
\text { condições associados ao uso da garantia }\end{array}$ \\
\hline 3 & Item 16 & $\begin{array}{l}\text { Conciliação das movimentações da conta durante o período para cada classe de ativos } \\
\text { financeiros }\end{array}$ \\
\hline 4 & $\begin{array}{c}\text { Item } 33 \\
\text { (a) }\end{array}$ & A exposição ao risco e como ele surge \\
\hline 5 & $\begin{array}{c}\text { Item } 33 \\
\text { (b) }\end{array}$ & $\begin{array}{l}\text { Os objetivos, políticas e processos para gerenciar os riscos e os métodos utilizados } \\
\text { para mensurar o risco }\end{array}$ \\
\hline 6 & $\begin{array}{c}\text { Item } 36 \\
\text { (b) }\end{array}$ & $\begin{array}{l}\text { Descrição da garantia mantida como título e valor mobiliário (security) e de outros } \\
\text { instrumentos de melhoria de crédito, e seus efeitos financeiros }\end{array}$ \\
\hline 7 & $\begin{array}{c}\text { Item } 36 \\
\text { (c) }\end{array}$ & $\begin{array}{l}\text { Informações sobre a qualidade do crédito de ativos financeiros que não estão } \\
\text { vencidos e tampouco com evidências de perdas }\end{array}$ \\
\hline 8 & $\begin{array}{c}\text { Item } 37 \\
\text { (a) }\end{array}$ & $\begin{array}{l}\text { Análise dos vencimentos dos ativos financeiros (aging analysis) que estão vencidos } \\
\text { ao final do período de reporte, mas para os quais não foi considerada perda por não } \\
\text { recuperabilidade }\end{array}$ \\
\hline 9 & $\begin{array}{c}\text { Item } 37 \\
\text { (b) }\end{array}$ & $\begin{array}{l}\text { Análise dos ativos financeiros que foram individualmente considerados sujeitos à } \\
\text { não } \\
\text { recuperabilidade (impaired) ao término do período de reporte, incluindo os fatores } \\
\text { que a entidade considerou determinantes para qualificá-los como tal }\end{array}$ \\
\hline 10 & $\begin{array}{c}\text { Item } 38 \\
\text { (a) }\end{array}$ & $\begin{array}{l}\text { A natureza e o valor contábil dos ativos para as garantias e outros instrumentos de } \\
\text { melhoria de crédito }\end{array}$ \\
\hline
\end{tabular}




\begin{tabular}{|c|c|c|}
\hline 11 & $\begin{array}{c}\text { Item } 38 \\
\text { (b) }\end{array}$ & $\begin{array}{l}\text { Quando os ativos não são prontamente conversíveis em caixa, a política adotada } \\
\text { pela entidade para alienação de tais ativos ou para seu uso em suas operações }\end{array}$ \\
\hline 12 & $\begin{array}{l}\text { Item } \\
40(\mathrm{a})\end{array}$ & $\begin{array}{l}\text { Análise de sensibilidade para cada tipo de risco de mercado aos quais a entidade está } \\
\text { exposta ao fim do período contábil }\end{array}$ \\
\hline \multicolumn{3}{|r|}{ ICVM no 489/11 } \\
\hline 1 & $\begin{array}{l}\text { Inciso I, \& } \\
8^{\circ}, \text { Art. } 17\end{array}$ & $\begin{array}{l}\text { O contexto operacional deve evidenciar os riscos incorridos pelos cotistas inerentes } \\
\text { aos investimentos }\end{array}$ \\
\hline 2 & $\begin{array}{l}\text { Inciso III (a) } \\
\text { e IV (a), § } \\
8^{\circ}, \text { Art. } 17\end{array}$ & $\begin{array}{l}\text { Descrição das características dos direitos creditórios adquiridos pelo fundo, } \\
\text { segregados em com e sem aquisição substancial de riscos e benefícios }\end{array}$ \\
\hline 3 & $\begin{array}{l}\text { Inciso III } \\
\text { (b) e IV (b), } \\
\S 8^{\circ} \text {, Art. } 17\end{array}$ & $\begin{array}{l}\text { Valor contábil dos direitos creditórios adquiridos na proporção dos riscos e } \\
\text { benefícios transferidos para o fundo (operações em que a aquisição substancial dos } \\
\text { riscos e dos benefícios não possa ser definida objetivamente) }\end{array}$ \\
\hline 4 & $\begin{array}{l}\text { Inciso } V, \S \\
8^{\circ}, \text { Art. } 17\end{array}$ & $\begin{array}{l}\text { Critérios, metodologias e avaliações adotados pela instituição administradora para a } \\
\text { definição da aquisição substancial ou não dos riscos e dos benefícios de propriedade } \\
\text { do direito creditório objeto da operação }\end{array}$ \\
\hline 5 & $\begin{array}{l}\text { Inciso VI, § } \\
8^{\circ}, \text { Art. } 17 \\
\end{array}$ & $\begin{array}{l}\text { Informar a carteira por data de vencimento, valor de provisão, tipo e natureza de } \\
\text { ativo, segregando os valores a vencer dos vencidos }\end{array}$ \\
\hline 6 & $\begin{array}{l}\text { Inciso VII, § } \\
8^{\circ}, \text { Art. } 17\end{array}$ & $\begin{array}{l}\text { Descrever as principais práticas de gerenciamento de riscos efetivamente adotadas } \\
\text { pelo fundo, notadamente em relação a riscos de crédito, liquidez e juros }\end{array}$ \\
\hline 7 & $\begin{array}{l}\text { Inciso VIII, } \\
\S 8^{\circ}, \text { Art. } 17\end{array}$ & Informar as taxas praticadas por grupo de operação realizada no exercício \\
\hline 8 & $\begin{array}{l}\text { Inciso IX, § } \\
8^{\circ}, \text { Art. } 17\end{array}$ & $\begin{array}{l}\text { Os critérios de coobrigação existentes em relação à inadimplência dos direitos } \\
\text { creditórios, previstos ou não no contrato de cessão, informando, inclusive, qual seria } \\
\text { o impacto no valor das cotas do fundo caso essa obrigação ou prática cessar. }\end{array}$ \\
\hline 9 & $\begin{array}{l}\text { Inciso X, § } \\
8^{\circ}, \text { Art. } 17\end{array}$ & $\begin{array}{l}\text { O valor total dos créditos readquiridos e substituídos no exercício pelo cedente, } \\
\text { informando o valor da aquisição, resultado auferido em cada operação, saldo } \\
\text { vincendo, se for o caso, e o motivo que deu origem à recompra e substituição }\end{array}$ \\
\hline 10 & $\begin{array}{c}\text { Inciso XI, § } \\
8^{\circ}, \text { Art. } 17 \\
\end{array}$ & A existência de garantias reais ou fidejussórias em favor do fundo \\
\hline 11 & $\begin{array}{l}\text { Inciso XII, \& } \\
8^{\circ}, \text { Art. } 17 \\
\end{array}$ & $\begin{array}{l}\text { O valor do estoque do mesmo devedor e o critério de mensuração do impacto nas } \\
\text { parcelas a vencer relativas ao mesmo devedor em outras operações }\end{array}$ \\
\hline 12 & $\begin{array}{l}\text { Inciso XIII } \\
\text { (a), \& } 8^{\circ} \\
\text { Art. } 17\end{array}$ & $\begin{array}{l}\text { Os critérios de avaliação e constituição, assim como a movimentação da provisão no } \\
\text { exercício, destacando a movimentação em função de mudanças de estimativas }\end{array}$ \\
\hline 13 & $\begin{array}{l}\text { Inciso XIII } \\
\text { (b), } \S 8^{\circ} \\
\text { Art. } 17\end{array}$ & $\begin{array}{l}\text { Os procedimentos adotados para realizar o acompanhamento dos direitos } \\
\text { creditórios, no que se refere à capacidade do devedor ou garantidor de honrar os } \\
\text { pagamentos }\end{array}$ \\
\hline 14 & $\begin{array}{l}\text { Inciso XIV, } \\
\S 8^{\circ}, \text { Art. } 17\end{array}$ & Motivos e condições na reclassificação de direitos creditórios \\
\hline 15 & $\begin{array}{l}\text { Inciso XXI, } \\
\S 8^{\circ} \text {, Art. } 17\end{array}$ & $\begin{array}{l}\text { A avaliação efetuada por agência classificado de risco, o período a que se refere e a } \\
\text { instituição avaliadora, e, se o fundo estiver dispensado da classificação de risco, } \\
\text { informar qual o fundamento regulatório da dispensa }\end{array}$ \\
\hline 16 & Art. 16 & $\begin{array}{l}\text { As estimativas e mudanças de estimativas que são requeridas para determinar o } \\
\text { custo amortizado }\end{array}$ \\
\hline
\end{tabular}

